\title{
FREQUENCY OF INJURIES AMONG ELITE BULGARIAN ATHLETES
}

\author{
A. Nikolova* \\ Department of Sports Medicine, National Sports Academy "Vasil Levski”, Sofia, Bulgaria
}

\begin{abstract}
Judo is martial art,which philosophy is very closely tied with its east-asian roots and it focuses on the contestant's physical and spiritual development. The aim of this study is to investigate the incidence of traumas in elite judo athletes from the Bulgarian national team, in a retrospective manner throughout their careers as athletes. A survey was conducted among 37 athletes from the Bulgarian national judo team. All competitors have received at least one injury during their competitive career. These are sprains, strains and contusions. Most of the traumas occur during training. The severe injuries occur during competition and in general are caused from the direct contact with the opponent. The present study has limitations such as the small focus group size. Thus suggested future studies involving other judo competitors, as well as coaches and judges. It's interesting to recognize their opinion and to compare it with that of the athletes. That will help to propose strategies for prevention of injuries.
\end{abstract}

Keys words: Judo, injuries

\section{INTRODUCTION}

Judo is characterised as modern martial art, and it has gained vast popularity around the world. Since 1972 the Judo has become an official Olympic discipline for men and since 1992 for women. Judo's philosophy is very closely tied with its east-asian roots and it focuses on the contestant's physical and spiritual development. This means keeping a good physical form as well as learning and applying many and various techniques. The aim of the sport is to defeat the opponent by putting him under control using various techniques. Techniques such as pinning techniques, choking techniques and joint locks. $[1,2]$ The combats follow the rules of the martial art and are monitored by a judge, who declares the winner. The contestants have to be fully prepared and therefore their training often

\footnotetext{
*Correspondence to: Anna Nikolova, Department of Sports Medicine, National Sports Academy

"Vasil Levski”, Studentski grad,1700 Sofia,

Bulgaria,e-mail:a_lucien@abv.bg, tel. +359898346483
}

involves combats that follow different study forms. There is a high risk of injury.[3].

Examining the various injuries among judo contestants is a favourite topic of many different studies. Some of them conclude that judo is very injury heavy sport. Others study the frequency of injuries during training and competition and conclude that the risk of injury is very high during study combats [4].

Most of the authors can't agree on standardised definition of injury. Some believe that the injuries are "primarily defined as damage inflicted on the body as the result of direct or indirect external force, with or without disruption of structural continuity." [4] others define it as lesion, in which case an urgent medical assistance is required. [5]. We have determined that this would be an injury that happens during exercise. [6] According to most of the authors, studying and examining of injuries among martial arts contestants, helps to define the risk factors that lead to an injury. Furthermore, the collected data helps to develop a prevention strategy for injury avoidance. $[7,4,8,9]$. We decided to study and 
characterize the frequency of injuries among: athletes from the Bulgarian national judo team.

The aim of this study is to investigate the incidence of traumas in elite judo athletes from the Bulgarian national team, in a retrospective manner throughout their careers as athletes.

\section{MATERIAL AND METHODS}

The study covers 37 elite athletes from the Bulgarian national judo team (18 men and 19 women). The study was conducted by selfadministered anonymous questionnaire.

The survey questions were formed following the ethical standards of the Helsinki Declaration as well as the ethical standards of the Ethical Board of the National Sports Academy. The questions were divided in two parts. First part focused on characteristics about the athlete's age, height, weight and competitive class. Furthermore, it included questions about the competitions they participated in, ranking, way of training and recovering activities. The second part was focused on the types of injuries and reasons that might lead to them, according to the surveyed, as well as types of treatments that they undertook. The data was statistically processed - using descriptive statistics, frequency and correlation analysis.

\section{RESULTS}

Thirty seven athletes with mean age $21.8 \pm 6.3$ years and mean sporting experience of $11.1 \pm 5.3$ years participated in this study. Most of them train approximately $16,8 \pm 3$ hours a week - 11 months a year. All contestants warm up with mean time $22,6 \pm 7,2 \mathrm{~min}$. They stretch for $15 \mathrm{~min}$ and additionally go to the gym 1-2 times a week. Most of them go to recovery on recovery sessions 1 time every two weeks, on average. This correlates with the data from other authors [10]. There is no significant difference in the markers between men and women. (Table 1).

\section{Table1. Training and recovering activities}

\begin{tabular}{|c|c|c|c|c|}
\hline Column1 & Total & men & woman & \\
\hline total count & & 7 & 18 & 19 \\
\hline middle-aged & $21,8 \pm 6,3$ & $21,6 \pm 7,8$ & $22 \pm 4,6$ & \\
\hline training practice & $11,1 \pm 5,3$ & $11 \pm 6,4$ & $11,2 \pm 4,2$ & \\
\hline middle-aged of receiving a first trauma & $16,8 \pm 3,5$ & $17,4 \pm 4$ & $16,3 \pm 3$ & \\
\hline training hours during the week & $15,7 \pm 7,5$ & $15,2 \pm 7,15$ & $16,1 \pm 8$ & \\
\hline training months & & 1 & 11 & 11 \\
\hline average minutes for heating & $21,6 \pm 7,2$ & $20 \pm 8,4$ & $23 \pm 5,8$ & \\
\hline average minutes for stretching & $14,5 \pm 6,8$ & $20 \pm 4,9$ & $13 \pm 5$ & \\
\hline an additional sport (fitness) & $1,8 \pm 0,8$ & $1,9 \pm 0,9$ & $1,8 \pm 0,8$ & \\
\hline \begin{tabular}{|l|} 
average doing recovery \\
\end{tabular} & $0,7 \pm 0,74$ & $0,6 \pm 0,6$ & $2,3 \pm 0,7$ & \\
\hline
\end{tabular}

$13.5 \%(\mathrm{n}=5)$ of the athletes did not report any injury, $32.4 \%(\mathrm{n}=12)$ had 1 injury, $18.9 \%$ $(n=7)$ had 2 injuries, and $24.3 \%(n=9)$ had 3 injuries, followed by $8.1 \%(n=3)$ who have had more than 4 injuries.Our results are similar to the results of Oliveira and Pereira [11].

The average age of getting the first injury is $16,85 \pm 3,5$ years. This correlates with the opinion that there is a disbalance in the tissue development during puberty. [12]

There is an equal amount of contestants that have gotten injury during training-32\% ( $\mathrm{n}=$ $12)$, and competition - 29.7\% ( $\mathrm{n}=11)$. $24.3 \%(n=9)$ athletes have had injury on both.
This doesn't correspond to the findings of some researches $[13,14,15]$ who point out that there is a higher risk of injury during competitions. Others believe that training is more prone to injury $[11,16]$. We believe that the amount of contestants that have gotten injury during competition and training has no significant difference because the questionnaire covers a long period of time - the whole competitive career of the athletes to the present moment.

Most of the injuries that happen during training occur during randori /training combats/. In competition the injuries usually are caused from attack or defence [16]. 
According to the type of the injury the most common were strains $-(n=15)-14 \%$, followed by torn muscles tissue $-(n=11)-10,2 \%$, or the tendon tissues $-(n=8)-7,4 \%$, contusions $(n=$
11)-10,2\% sprains $(n=11)-10,2 \%$, meniscus $(n=7)-6,5 \%$ and fractures $(n=7)-6,5 \%$. That correlates with literature data [4]. Figure 1

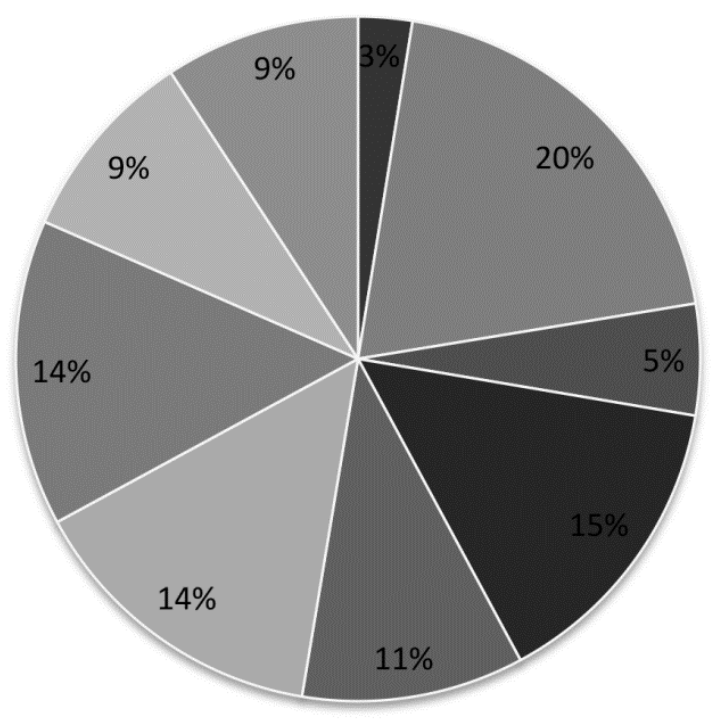

$$
\begin{aligned}
& \text { wond } \\
& \text { n strain } \\
& \text { - cramp } \\
& \text { - tears m.f. } \\
& \text { a ters m. } \mathrm{t} \text {. } \\
& \text { aruise } \\
& \text { - luxation } \\
& \text { - tears men. } \\
& \text { - fractura }
\end{aligned}
$$

Figure 1. Type of injury

Altogether for the entire research period 37 athletes have gotten 107 injuries in total on different parts of their bodies. We should note that the same athlete can have different types of injuries sometimes even on the same location, during their competitive career.
Most of the injuries are located in the lower limbs predominantly in the knee area $(n=22)$ $20,5 \%$ and ankle $(n=13)-12 \%$ followed by in the upper limbs, most commonly in the shoulder $-(n=11)-10,2 \%$. That corresponds to literature data $[4,10]$. Figure 2

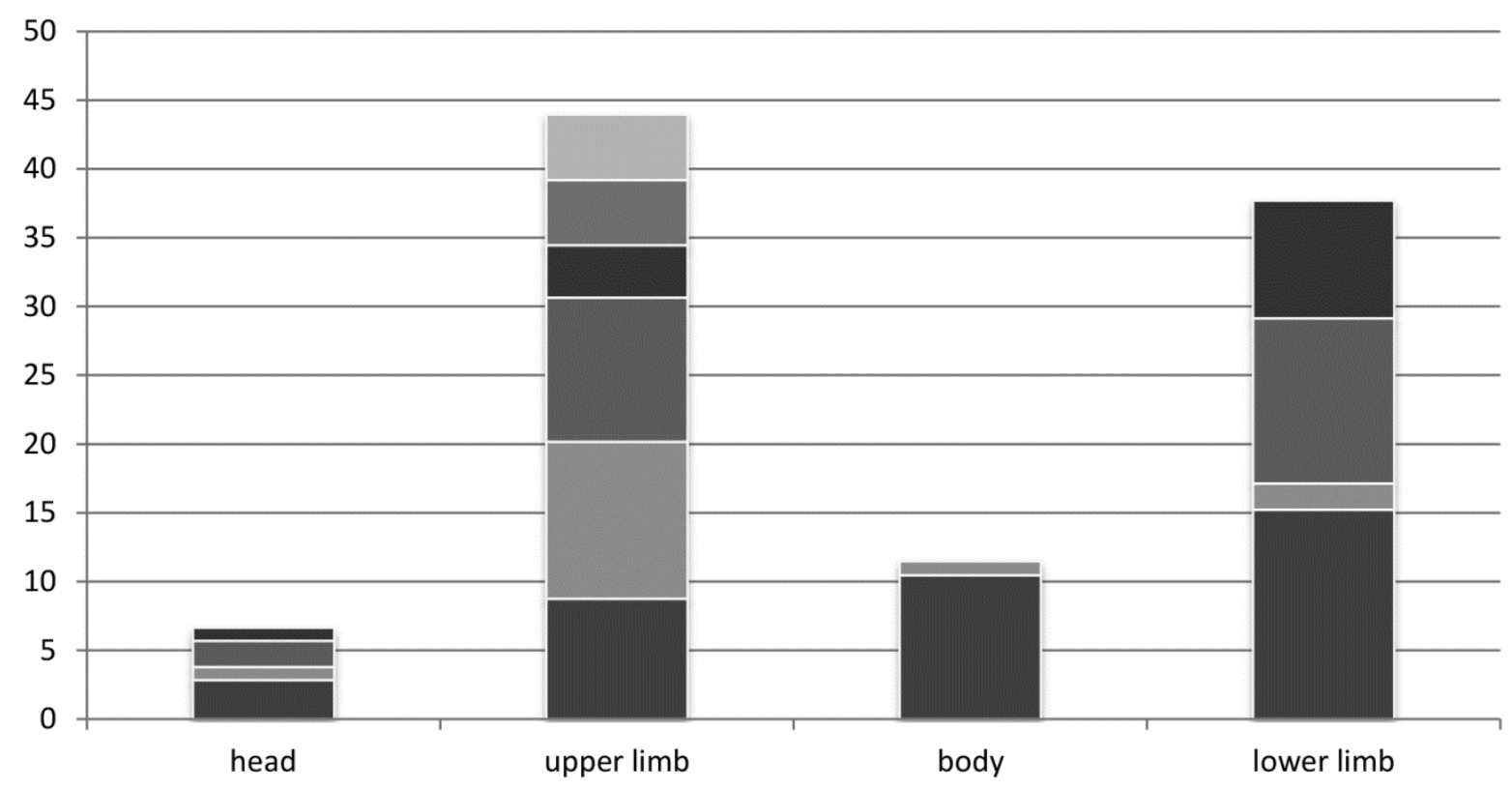

Figure 2. Localization of injuries

Medications are predominantly used for treatment - $(n=19)-23,7 \%$, combined with physiotherapy $-(\mathrm{n}=17)-21,3 \%$ and rest $(\mathrm{n}=18)-22,5 \%$ [10]. Figure 3 


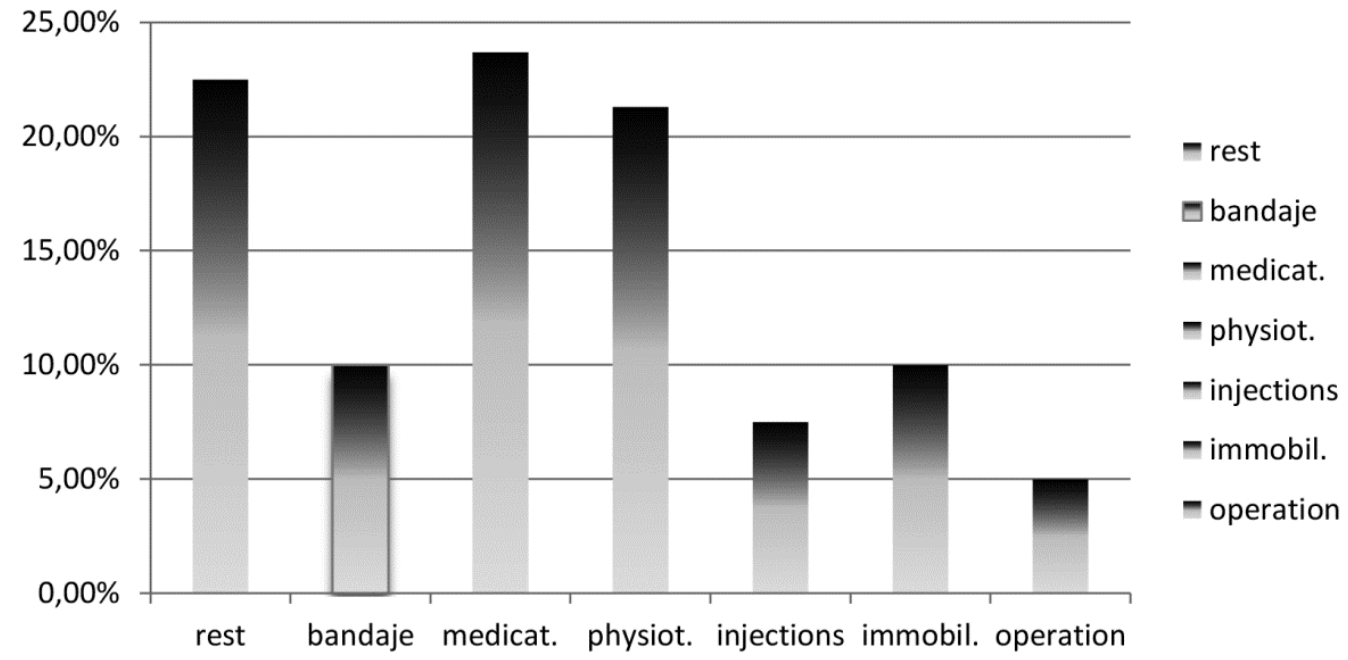

Figure 3. Treatment

Only $9 \%(n=3)$ did not have to miss training or competition due to injury $39,3 \%(n=13)$ were absent for more than 1 month and 27\%(n=9) for 3-4 weeks. We can categorise the absence as follows: light injuries for absence $\leq 7$ days, medium injuries for absence between 8 and 28 days and heavy injuries for more than 28 days [17]. This means that more than half of the athletes have gotten a heavy injury. Figure 4
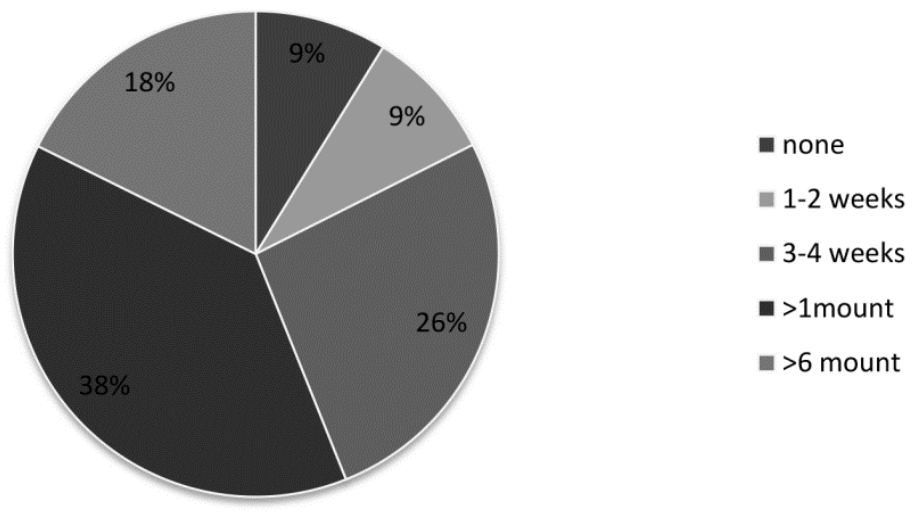

Figure 4. Time of absence from training and competitions

\section{DISCUSSION}

The study was conducted among elite Bulgarian judo competitors, which explains the bigger predisposition for injury. The definition which we used for injury is any type of injury caused during training. Furthermore, the larger number of reported injuries -107 also influence the study. Long competitive career, constant training, frequent contest participation and strive for self-improvement are a big predisposition for injury and they account for $2-2,5 \%$ on average of 11 year of sports career. The injuries can be received during training or contest. Most of their causes are direct contact with the opponent or fatigue. Due to the Judo's specific techniques, connected with twisting and turning of the body, the soft tissue injuries predominated among the contestants. The most affected areas are the lower limbs, and the injuries that predominate are sprains and strains, torn muscles tissue and torn tendon, injuries and luxation. Even though Medications are predominantly used for treatment and physiotherapy, still $39 \%$ of the athletes had to be absent from training in order to recover. The present study has limitations such as the small focus group size. Thus suggested future studies involving other judo competitors, as well as coaches and judges. It's interesting to recognize their opinion and to compare it with that of the athletes. That will help to propose strategies for prevention of injuries. 


\section{REFERENCES}

1.Dimitrova N.; Pendeva 2010, "Realizatsionna efficiency of Shime-waza in judo" Sport \& Science number №2; pp. 79-84; Type - Top Press; Sofia, ISSN 1310339

2. Dimitrova N., Pendeva M., Nasiyev Er. 2017; "Implementation effectiveness of locking techniques (kansetsu-waza) in judo"; Scientific Conference "Challenges and Prospects for Sports Science", "Specifics of Preparation in Different Sports Disciplines" - 2016; IDC NSA PRESS; p.40-45; Sofia, ISBN 978-954718-457-2

3.Trajković Nebojša, Dejan Madić, Nebojša Maksimović, Zoran Milošević, Borislav Obradović, Nikolina Dimitrova, Patrik Drid, Evaluating injury risk in female karate athletes: bilateral and unilateral asymmetries of isokinetic strength", 14th International Scientific Conference of Sport Kinetics 2018, "Movement in Human Life and Health", Poreč, Croatia, 24th -27 th June 2018 (This proceedings book is also available in e-format.,ISBN (hard copy): 978-86-6353-025-6, ISBN (pdf, online): 978-86-6353-026-3, ISBN (hard copy): 978-953-317-058-9)

4. Pocecco E,Ruedl G,Stankovic Nqet al.Injuries in judo: a systematic literature review including suggestions for prevention. Br J Sports Med 2013;47;113911430

5. Maciejewski R.S. et all Epidemiology of judo Injuries in Senior and Junior Judoka, Scientific Review of Physical Culture, volume 6 , issue 3

6. Dimitrova D. 2017, The fundamentals of sports medicine-Avangard Prima, Sofia, 2017, ISBN 978-619-160-904-8

7.Oliveira TS, Pereira JS.Frequency of articulation injuries in judo practicing.Fit Perf J. 2008 Nov-Dec;7[6]:375-6.Pieter W. De Cree C. Competition injuries in young and adult judo athletes.Abstract book of the Second Annual Congress of the European College of Sport
Science.Copenhagen,Denmark:Springer, 19 97:709-16

8.Albert, M. 2017; Examination of the impact of medicinal massage combined with deep occurrence in the healing process of patients with worldwrite. International Journal Knowwlege in Scientific Papers, Vol 19, 4, Scopie, Pp1467-1473, ISSN 1857-923X.

9. Berzarova W., M. Albert, T. Dimitrov. 2017, Compression Diagnostic Method ofN. Femoralis in shortening lig. Inguinalis; Health and Science, Year VII, No. 1, pp. 25-29. ISSN 1314-3360

10. Minghelli B. and Isidoro R. Prevalence of Injuries in Jiu-Jitsu and Judo Athletes of Portugal South: Associated Injury Mechanisms 2016,J Community Med Health Educ 2016,6:3, http://dx.doi.org./10.4172/216110711.1000441

11. Oliveira, Pereira Osteomyoarticular injuries in Judo practitiones Fit Perf J.2008 Nov- Dec;7(6);375-9

12. James F. Scoggin III, MD, et all Assessment of Injuries During Brazilian Jiu-Jitsu Competition, 2014 The Orthopaedic Journal of Sports Medicine, 2(2), $232596 \quad 7114522184$ DOI: $10.1177 / 2325967114522184$

13. Cynarski WJ, Kudlacz M.Injuries in martial arts and combat sports-a comparative study. Arh Budo 2008; 4; 91-7

14.Engebretsen L.,Soligard T.,Steffen K.,et al. Sports injuries and illnesses during the London Summer Olympic Games 2012.Br J Sports Med 2013;47;407-14

15. Souza M, Monteiro H, Del Vecchino F, et al.Referring to judo`s sports injuries in Sao Paulo State Championship. Sci Sports 2006; $21 ; 280-4$

16. Oliveira, Pereira Osteomyoarticular injuries in Judo practitiones Fit Perf J.2008 Nov-Dec; 7 (6);375-9.

17. Manzato A.L.G. et all 2017, Musculoskeletal injuries in judo practitioners, DOI: 10.1590/18092950/16325024022017 